\title{
Analysis of the nucleolar organizing regions in the ant Tapinoma nigerrimum (Hymenoptera, Formicidae)
}

\author{
P. LORITE, A. E. ARÁNEGA, F. LUQUE \& T. PALOMEQUE* \\ Departamento de Biología Experimental, Area de Genética, Universidad de Jaén, 23071 Jaén, Spain
}

\begin{abstract}
This study analyses the NORs of Tapinoma nigerrimum, a species that, as known from previous studies, has various chromosomes which carry a NOR site. The analysis was made by a combination of three methods: silver nitrate staining, in situ hybridization with fluorescein- or digoxigenin-labelled probes, and staining with the $\mathrm{CG}$-specific fluorochrome chromomycin $\mathrm{A}_{3}$. The silver staining technique showed an Ag-positive region on chromosome 6 and on various other chromosomes. However, the application of in situ hybridization techniques showed only one positive signal in the proximal region of the short arm of chromosome 6 of T. nigerrimum. Similar results were observed by CMA banding. The absence of rDNA genes or the presence of only a small number of these, not detectable with the above probes, might explain the absence of hybridization signal in the remaining chromosomes.
\end{abstract}

Keywords: Ag-NORs, ants, fluorescent CMA bands, in situ hybridization.

\section{Introduction}

In eukaryotic genomes the genes (the rDNA) for ribosomal RNA are arranged as clusters of tandemly repeated units. It is well known that profiles of the chromosomal distribution of RNA, such as the number of chromosomal loci and the number of genes at each locus, vary among species, among populations and among individuals. These features of the NORs have been demonstrated either by silver staining techniques or by in situ hybridization. The latter technique can detect all clusters of rDNA, whereas the former specifically identifies transcriptionally active rDNA cistrons, the so-called silver stainable nucleolar organizer regions (Ag-NORs). It is also well known that there are two different types of rDNA, active and inactive, although the mechanism controlling the difference is not known.

In a previous article (Palomeque et al., 1988) we have reported the existence in Tapinoma nigerrimum of an Ag-positive region (or Ag-NOR) in chromosomes 6 and 8 . Amongst the remaining chromosomes, the number of chromosomes bearing an $\mathrm{Ag}$-positive region varied between individuals and populations. In this article we report an analysis of the nucleolar organizing regions of $T$. nigerrimum

\footnotetext{
*Correspondence. E-mail: tpalome@jabalcuz.ujaen.es
}

using silver nitrate, in situ hybridization with fluorescein- or digoxigenin-labelled probes, and chromomycin $\mathrm{A}_{3}$ (CMA) staining. The silver staining technique showed an Ag-positive region on chromosome 6 and on various other chromosomes. However, only one positive signal in the proximal region of the short arm of chromosome 6 was observed using the in situ hybridization techniques. A similar result to the in situ hybridization was obtained by CMA banding techniques.

\section{Materials and methods}

The samples analysed were collected in different sites in Almería (Southern Spain).

\section{Chromosome preparations}

Chromosome preparations were made from germ cells of early male and female pupae using the technique described by Meredith (1969).

\section{Ag-stain}

Silver nitrate stainings were performed according to the techniques described by Howell \& Black (1980) and Rufas et al. (1982). 


\section{$D A / C M A, D A / D A P I$ stain}

Staining with DA/CMA and DA/DAPI was performed according to the techniques of Schweizer et al. (1979) and Schweizer (1980).

\section{DNA probe}

For Southern hybridization and in situ hybridization we used a plasmid containing the Drosophila rDNA gene (pDm r.a 51\#1) provided by Dr S. A. Endow from Duke University Medical Center. This plasmid consists of a noninterrupted $11.5 \mathrm{~kb}$ repeat unit and encodes noninterrupted rRNA genes (18S and 28S; Endow, 1982).

\section{Endonuclease digestion and Southern hybridization}

Isolated nuclear DNAs, $10 \mu \mathrm{g}$, were digested with restriction enzymes EcoRI and SmaI according to the manual of the supplier (Boehringer Mannheim). Digestion fragments were separated on a 0.8 per cent agarose gel, then blotted onto Hybond-N membranes (Amersham) under standard conditions.

The Southern hybridization was performed according to the technique described by Sambrook et al. (1989). The probe was labelled with digoxigenin-11-dUTP using a random primer DNA labelling kit (Boehringer Mannheim). The hybridization conditions were set at high stringency, in a solution containing $5 \times \mathrm{SSC}$ overnight at $68^{\circ} \mathrm{C}$. Detection of hybridization was performed with a DIG-detection kit from Boehringer-Mannheim.

\section{In situ hybridization}

One $\mu \mathrm{g}$ of DNA probe was labelled with digoxigenin-11-dUTP using a random primed DNA labelling kit (Boehringer Mannheim) for $2 \mathrm{~h}$ at $37^{\circ} \mathrm{C}$, or with fluorescein-12-dUTP by a nick-translation procedure (Sambrook et al., 1989). The labelled probe was precipitated with sodium acetate $3 \mathrm{M}$ and ethanol at $-20^{\circ} \mathrm{C}$ and dissolved in $100 \mu \mathrm{L}$ of 50 or 30 per cent formamide and stored at $4^{\circ} \mathrm{C}$ until used directly for hybridization. Prior to hybridization, slides were treated with RNase A, pepsin and formaldehyde and dehydrated in 70 per cent, 90 per cent and 100 per cent ethanol for $5 \mathrm{~min}$ each. Hybridization was performed applying $25 \mu \mathrm{L}$ of DNA-labelled solution to each slide, which was heated for $5 \mathrm{~min}$ at $80^{\circ} \mathrm{C}$ to denature the DNA, and immediately chilled on ice for $3 \mathrm{~min}$. The slides were transferred to a moist chamber humidified with formamide ( 30 per cent or 50 per cent) and incubated overnight at $37^{\circ} \mathrm{C}$. After incubation, the slides were washed in 50 or 30 per cent formamide for $10 \mathrm{~min}$ at $37^{\circ} \mathrm{C}$, washed twice in $2 \times$ SSC for $5 \mathrm{~min}$ each and once in TNT $(0.1 \mathrm{M}$ Tris$\mathrm{HCl}, 0.15 \mathrm{M} \mathrm{NaCl}, 0.05$ per cent Tween-20, pH 7.5) for $5 \mathrm{~min}$. After the washing step, the slides with fluorescein-labelled probe were dehydrated and mounted with $50 \mu \mathrm{L}$ of a propidium iodide solution ( $1 \mu \mathrm{L}$ propidium iodide in $\mathrm{PBS} / \mathrm{mL}$ of Vectashield) and observed with a fluorescence microscope, using an excitation filter of $460-490 \mathrm{~nm}$, IB (Olympus Optical Co. Ltd., Tokyo, Japan). Photographs were taken with a B\&W Kodak Technical Pan. The slides with a digoxigenin-labelled probe were washed in TNT, and then blocked with $100 \mu \mathrm{L}$ of TNB $(0.1 \mathrm{~m}$ Tris- $\mathrm{HCl}, 0.15 \mathrm{M} \mathrm{NaCl}, 1$ per cent Boehringer Mannheim blocking reagent) at $37^{\circ} \mathrm{C}$ for $30 \mathrm{~min}$. Hybridization was detected using the DIG-detection kit from Boehringer Mannheim, and observed with an optical phase-contrast microscope.

\section{Results and discussion}

The chromosome number of $T$. nigerrimum is $n=9$ in haploid males and $2 n=18$ in diploid females and workers. The haploid karyotype formula is $n=5 \mathrm{~m}+2 \mathrm{sm}+2 \mathrm{st}$ (Palomeque et al., 1988).

Previous articles reported the existence in $T$. nigerrimum of an $\mathrm{Ag}$-positive region (or Ag-NOR) in all chromosomes of the complement, although there were interpopulation differences in relation to the number of chromosomes bearing an $\mathrm{Ag}$-positive region. Chromosomes 6 and 8 showed an Ag-NOR in all populations studied. Amongst the remaining chromosomes, the number of chromosomes bearing an $\mathrm{Ag}$-positive region varied between individuals and populations. In all cases, the positive Ag-regions were adjacent to the respective centromeric regions and coincident with positive C-banding sites (Palomeque et al., 1988, 1990).

In this study the analysis of NORs was made by a combination of three methods: silver nitrate staining, in situ hybridization with fluorescein- or digoxigenin-labelled probes, and staining with the fluorochrome chromomycin $\mathrm{A}_{3}$. In situ hybridization techniques were carried out on chromosome preparations of haploid males and diploid females.

The silver staining technique showed an Ag-positive region in chromosome 6 and on various other chromosomes (Fig. 1). These results are similar to those obtained in other populations (Palomeque $e t$ al., 1990).

In situ hybridization techniques were carried out using Drosophila rDNA as a probe. As shown in Fig. 2a, nucleotide sequences homologous to the 
rDNA of Drosophila were detected in the Tapinoma nuclear genome. This result was obtained under high stringency conditions. Homologous nucleotide sequences between Drosophila rDNA and the nuclear genome of the Myrmecia ant have also been detected (Imai et al., 1992; Hirai et al., 1994).

In situ hybridization using fluorescein-labelled probes showed only one positive signal situated in the short arm of chromosome 6 , near the centro-

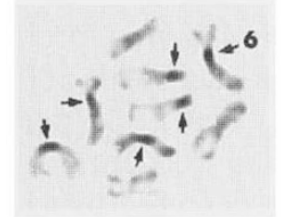

Fig. 1 Tapinoma nigerrimum. Haploid metaphase plate showing an $\mathrm{Ag}$-positive region on chromosome 6 and on various other chromosomes (arrows). meric region (Fig. 2b). A similar result was obtained by in situ hybridization using digoxigenin-labelled probes (Fig. 2c). Two positive signals occurring in the two homologous chromosomes 6 were identified in the chromosome preparations of diploid females (Fig. 2d). In both hybridization techniques, similar results were obtained under low and high stringency conditions. The hybridization technique using digoxigenin-labelled probes was also applied under overexposure conditions (data not shown). Only one positive signal on chromosome 6 was obtained.

Only the proximal region of the short arm of chromosome 6 showed a differential fluorescence after staining with CMA, indicating that it is particularly rich in $\mathrm{C}-\mathrm{G}$ base pairs, like the majority of the NORs in eukaryotic genomes (Schmid \& Guttenbach, 1988; Cerbah et al., 1995; Reed \& Phillips, 1995). A CMA-negative region coincident with a DAPI-positive region (Lorite et al., 1996) is also observed in this chromosome (Fig. 2e).

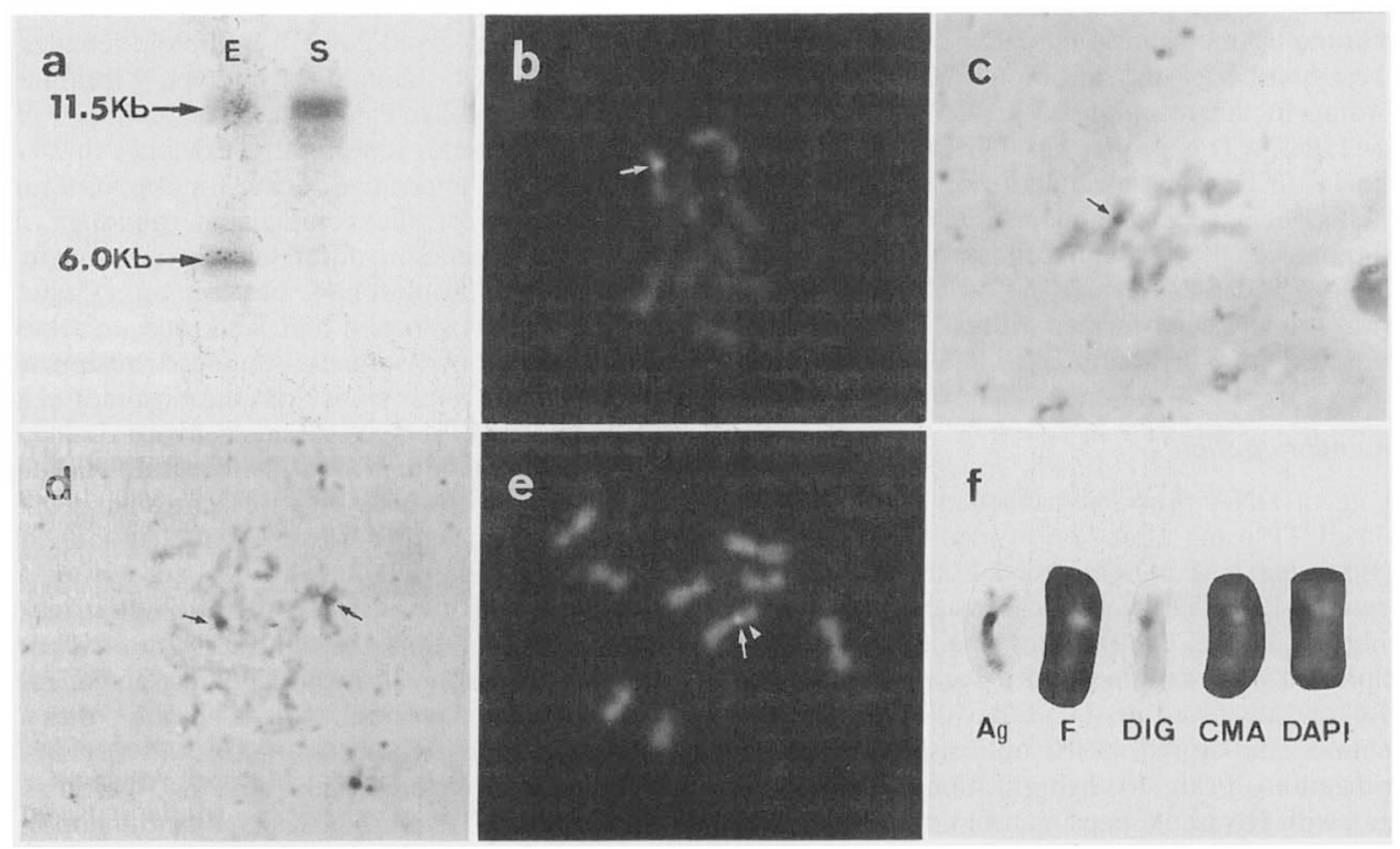

Fig. 2 (a) Southern hybridization of Tapinoma nigerrimum genomic DNAs with Drosophila melanogaster rDNAs. DNAs digested with EcoRI (E) and SmaI (S) were separated on 0.8 per cent agarose gel. (b-d) In situ hybridization with rDNA; (b) haploid metaphase using fluorescein-labelled probes, showing only one positive signal in the short arm of chromosome 6 (arrow); (c, d) haploid and diploid metaphases after in situ hybridization using DIG-labelled probes and detected by alkaline phosphatase, showing also one site of hybridization on chromosomes 6 (arrows). (e) Haploid metaphase plate showing only one region with differential CMA staining on the short arm of chromosome 6 (arrow) adjacent to one CMA-negative region (arrowhead). (f) Chromosome 6 from different metaphases observed after silver nitrate staining $(\mathrm{Ag})$, in situ hybridization with fluorescein $(\mathrm{F})$ and digoxigenin (DIG)-labelled probes, CMA banding and DAPI banding. 
In accordance with all the results shown here, the rDNA seems to be present only on chromosome 6 . The rDNA genes are in an Ag-positive, CMA-positive, DAPI-negative chromosomal region and are coincident with the positive signal obtained by hybridization techniques (Fig. 2f).

In situ hybridization to chromosomal DNA is a technique which allows specific detection of single nucleic acid sequences in morphologically preserved biological specimens. Fluorescence in situ hybridization (FISH) is an easy, sensitive nonradioisotopic method for localizing probes in different chromosomes (Larin et al., 1994). In addition to many practical advantages, the sensitivity of FISH to metaphase chromosomes is now nearly equivalent to that of in situ hybridization using radioactive probes (Lemieux et al., 1992). A significant improvement in fluorescence in situ hybridization enabling the detection of single-copy genes as small as 500 bp directly on banded chromosomes has been well reported (Lemieux et al., 1992).

In spite of this, the absence of rRNA genes, or the presence of only a small number of these, not detectable with the probes used here, might explain the absence of signal in the remaining chromosomes. On the other hand, other authors have shown that silver also stains chromosomal regions other than NORs. In rye, for example, silver nitrate stains not only the NOR sites but also all regions of constitutive heterochromatin (Murray et al., 1992). Sánchez et al. (1995) have also observed that silver stains the NORs and the heterochromatic blocks in hedgehogs. Silva et al. (1995) have reported that in Aegilops umbellulata and Secale cereale the silver banding pattern is coincident with the banding pattern obtained after FISH, using as a probe a repetitive sequence isolated from rye.

\section{Acknowledgement}

We are very grateful to Dr S. A. Endow from Duke University Medical Center (USA) for providing us with the Drosophila rDNA probe, and to Dr Imai from the National Institute of Genetics of Mishima (Japan) and Dr Hirai of Kyoto University (Japan) for their critical reading of the manuscript. We are also very grateful to Dr S. Valera from the University of Jaén (Spain) for revising the English style of the manuscript.

\section{References}

CERBAH, M., COULAUD, J., GODELlE, B. AND SILJAK-YAKOVIEV, s. 1995. Genome size, fluorochrome banding, and karyotype evolution in some Hypochoeris species. Genome, 38, 689-695.

ENDOW, S. A. 1982. Polytenization of the ribosomal genes on the $\mathrm{X}$ and $\mathrm{Y}$ chromosomes of Drosophila melanogaster. Genetics, 100, 375-385.

hiRA, H., YAMAMOTO, M. T., OGURA, K., SATTA, Y., YAMADA, M., TAYLOR, R. W. AND 1MAI, H. T. 1994. Multiplication of $28 \mathrm{~S}$ rDNA and NOR activity in chromosome evolution among ants of the Myrmecia pilosula species complex. Chromosoma, 103, 171-178.

HOWELL, W. M. AND BLACK, D. A. 1980. Controlled silverstaining of nucleolus organizer regions with a protective colloidal developer: a 1-step method. Experientia, 36, 1014-1015.

IMAI, H. T., hIRAI, H., SATTA, Y., SHIROISHI, T., YAMADA, M. AND TAYLOR, R. W. 1992. Phase specific Ag-staining of nucleolar organizer regions (NORs) and kinetochores in the Australian ant Myrmecia croslandi. Jap. J. Genet., 67, 437-447.

LARIN, Z., FRICKER, M. D., MAHER, E., ISHIKAWA-BRUSH, Y. AND SOUTHERN, E. M. 1994. Fluorescence in situ hybridisation of multiple probes on a single microscope slide. Nucl. Acids Res., 22, 3686-3692.

LEMIEUX, N., DUTRILlAUX, B. AND VIEGAS-PÉQUIGNOT, E. 1992. A simple method for simultaneous R-or G-banding and fluorescence in situ hybridization of small single-copy genes. Cytogenet. Cell Genet., 59, 311-312.

LORITE, P., CHICA, E. AND PALOMEQUE, T. 1996. G-banding and chromosome condensation in the ant Tapinoma nigerrimum. Chromosome Res., 4, 77-79.

MEREDITH, R. 1969. A simple method for preparing meiotic chromosomes from mammalian testis. Chromosoma, 26, 254-258.

MURRAY, B. G., BENNETT, M. D. AND HAMMETT, K. R. W. 1992. Secondary constrictions and NORs of Lathyrus investigated by silver staining and in-situ hybridization. Heredity, 68, 473-478.

PAlOMEQUe, T., CHICA, E., CANO, M. A. AND DÍAZ DE LA GUARDIA, R. 1988. Karyotypes, C-banding and chromosomal location of active nucleolar organizing regions in Tapinoma (Hymenoptera, Formicidae). Genome, 30, $277-280$

PAlOMEQUe, T., CHICA, E. CANO, M. A. AND díaZ DE LA GUARDIA, R. 1990. Development of silver stained structures during spermatogenesis in different genera of Formicidae. Genetica, 81, 51-58.

REED, K. M. AND PHILLIPS, R. B. 1995. Molecular cytogenetic analysis of the double-CMA $\mathrm{C}_{3}$ chromosome of lake trout, Salvelinus namaycush. Cytogenet. Cell Genet., 70, 104-107.

RUfAS, J. S., ITURRA, P., DESOUZA, W. AND ESPONDA, P. 1982. Simple silver staining procedures for the location of nucleolus and nucleolar organizer under light and electron microscopy. Arch. Biol., 93, 267-274.

SAMBROOK, J., FRITSCH, E. F. AND MANIATIS, T. 1989. Molecular Cloning, 2nd ed. Cold Spring Harbor Laboratory Press, Cold Spring Harbor, NY.

SÁNCHEZ, A., JIMÉNEZ, R., BURGOS, M., STITOU, S., ZURITA, F. AND díAZ DE LA GUARdiA, R. 1995. Cytogenetic pecu-

(c) The Genetical Society of Great Britain, Heredity, 78, 578-582. 
liarities in the Algerian hedgehog: silver stains not only NORs but also heterochromatic blocks. Heredity, 75, $10-16$.

SCHMID, M. AND GUTTENBACH, M. 1988. Evolutionary diversity of reverse $(\mathrm{R})$ fluorescent chromosome bands in vertebrates. Chromosoma, 97, 101-114.

SCHWEIZER, D. 1980. Simultaneous fluorescent staining of R-bands and specific heterochromatin regions (DA/DAPI bands) in human chromosomes. Cytogenet. Cell Genet., 27, 190-193.
SCHWEIZER, D., AMBROS, P., ANDRLE, M., RETT, A. AND FIEDLER, w. 1979. Demonstration of specific heterochromatin segments in the orangutan (Pongo pygmaeus) by a distamycin/DAPI double staining technique. Cytogenet. Cell Genet., 24, 7-14.

SILVA, M., NEVES, N., AMADO, L., CASTILHO, A., MORAISCECÍlIO, L., RESSUREIÇĀO, F. ET AL. 1995. Identification of DNA sequences associated with silver chromosome bands. 12th International Chromosome Conference. Chromosome Res., 3 (Suppl. 1), 61. 